\title{
Designing the core zone in a biosphere reserve based on suitable habitats: Yancheng Biosphere Reserve and the red crowned crane (Grus japonensis)
}

\author{
Wenjun $\mathrm{Li}^{\mathrm{a}}$,b,*, Zijian Wang ${ }^{\mathrm{a}}$, Zhijun $\mathrm{Ma}^{\mathrm{a}}$, Hongxiao Tang ${ }^{\mathrm{a}}$ \\ ${ }^{a}$ SKLEAC, Research Center for Eco-Environmental Sciences, PO Box 2871, Beijing 100085, People's Republic of China \\ ${ }^{\mathrm{b}}$ Center for Environmental Sciences, Peking University, Beijing 100871, People's Republic of China
}

\begin{abstract}
Although much research has been undertaken to design nature reserves, there are few practical methods to determine the interior structure of a reserve. A procedure for design of the core zone in reserves is proposed. As a case study, the core zone in Yancheng Biosphere Reserve, People's Republic of China, which was established to preserve the endangered red crowned crane (Grus japonensis) is designed. A statistical habitat model using geographic information system (GIS) is developed to predict crane presence or absence. Based on predicted suitable habitats, the minimum core zone is defined. More suitable habitats can be contained in the designated core zone, and this will be beneficial to the conservation and restoration for crane habitats. (C) 1999 Elsevier Science Ltd. All rights reserved.
\end{abstract}

Keywords: Reserve programme; Core zone; Habitat model; Geographical information system; Red crown crane

\section{Introduction}

A biosphere reserve is a protected area of representative environments, internationally recognized for their conservation value and for providing the scientific knowledge, skills and human values to support sustainable development (UNESCO, 1987). A biosphere reserve normally consists of three components: one or several core zones, a buffer zone, and a transition zone, each with different characteristic conservation roles. The core zone is strictly protected according to well-defined conservation objectives and should be a typical example of natural or minimally disturbed ecosystem. It should have a definite boundary and should have no human interference. The core area is normally surrounded by a buffer zone, which also must be strictly delineated. Only activities that do not conflict with the protection of the core zone are allowed within the buffer zone (IUCN, 1987). The core and buffer zones are surrounded by a transition zone which as a whole is usually not strictly

\footnotetext{
* Corresponding author at present address: Center for Environmental Sciences, Peking University, Beijing 100871, People's Republic of China. Tel.: + 86-10-6275-5643; fax: + 86-10-6275-1927.

E-mail address: wjlee@ces.pku.edu.cn (Wenjun Li)
}

delineated. It normally extends the core and buffer areas into a larger open area where efforts are made to develop cooperative activities among researchers, managers and the local inhabitants, with a view to ensuring the greatest possible harmony with the purpose of the biosphere reserve (Toxopeus and Wijingaarden, 1994).

Many studies have been carried out to select or determine the shape, size and the optimal site of reserves (Diamond, 1967; MacArthur and Wilson, 1967; Higgs and Usher, 1980; Higgs, 1981; Margules et al., 1982; Buckley, 1982; Blouin and Connor, 1985; Usher, 1986). Nevertheless, there are few available criteria for designing the interior structure of a reserve, such as the core zone.

In practice, designing the core zone necessitates coordinating the likely conflict between natural conservation and regional economic development. On the one hand, the core area may not be as large as it could be, especially when the need for such compromise arises. On the other hand, in addition to the occupied suitable habitats there are many unoccupied potential habitats which may become available when the population of the species increases or food resources are scarce. For practical conservation, any suitable or potentially suitable habitats should not be neglected in the design of the core. Practical design of core areas for most of the reserves in 
China has simply involved encircling the area where the preserved species are frequently observed. This method has led to the irreversible loss of potentially suitable habitats. Scientific design of the core zone therefore becomes increasingly important.

\subsection{Study site}

Yancheng Biosphere Reserve (YBR) was established in 1983 with the main aim of protecting an endangered bird species, the red crowned crane (Grus japonensis). It was approved as an international biosphere reserve in UNESCO's Man and Biosphere Program in 1992. The reserve is located in Jiangsu Province, east coast of China, and extends $582 \mathrm{~km}$ along the coast of the Yellow Sea. YBR is a typical coastal wetland with a total area of 280,000 ha. Its latitude is $32^{\circ} 34^{\prime}-34^{\circ} 28^{\prime}$, and longitude $119^{\circ} 48^{\prime}-120^{\circ} 56^{\prime}$. It is the largest wintering habitat for red crowned cranes in the world, the total number was 361 in 1983, increasing to 845 in 1994. The geographic distribution of cranes observed during 19911994 (Management Office of YBR, 1995) is shown in Fig. 1, in which the areas where cranes were present are defined as active sites.

The original core zone in YBR (Fig. 1) was simply delineated along the boundary of the area where the cranes were most frequent in 1983, when YBR was first established. However, many potential habitats have recently come into use as the population increase, and it can be seen that many active sites are outside the original core.

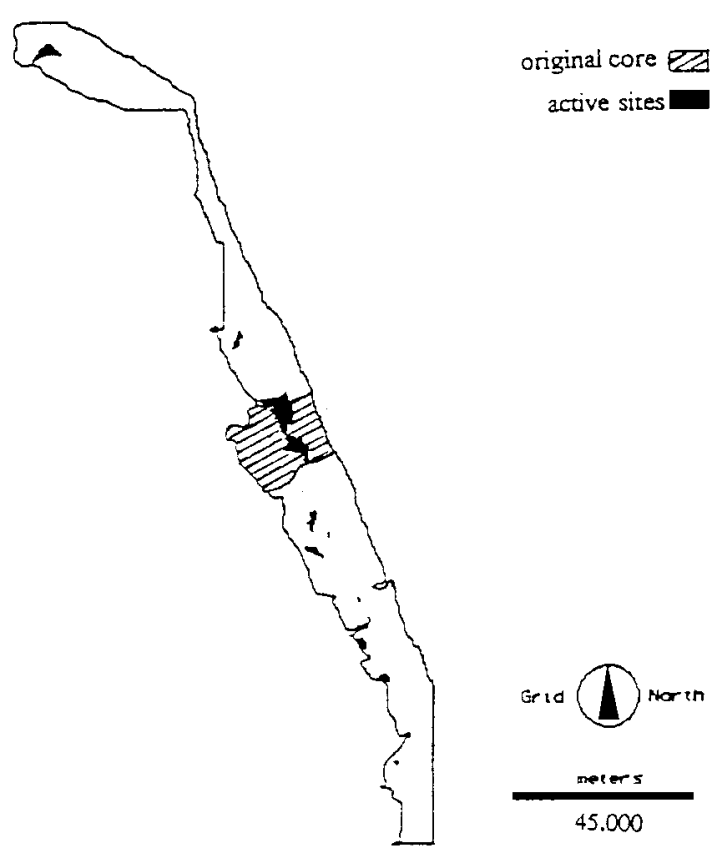

Fig. 1. Observed habitat distribution during 1991-1994, and original core allocation in YBR. YBR refers to the whole area inside the boundary.
In this paper, we put forward a procedure for designing the core zone, taking YBR as a case study. The principle followed is that the occupied and potential suitable habitat, rather than the present frequency of the species, is the factor on which decisions should be based. A habitat model based on Geographic Information System (GIS) is constructed to predict presence or absence of cranes, the dichotomous dependent variable. The independent variables are a set of environmental factors. Finally a new core zone is determined based on predicted habitats.

\section{Methodology}

The GIS software ARC/INFO (version 7.02 for workstation), published by Environmental Sciences Research Institute, US, was applied for processing and analyzing the variables using a DEC workstation. The grid format of variable data was used, and the cell size was $60 \times 60 \mathrm{~m}$.

\subsection{Description of variables}

Habitat surveys (Liu, 1990; Yan, 1991; Management Office of YBR, 1995) showed that cranes prefer to live in the upper tidal mudflat in which the salinity is lower. As in all the coastal wetland, the soil salinity within YBR decreases from seaboard (near the right boundary in Fig. 1) to inland (near the left boundary in Fig. 1). Thus few cranes occur along the coastline. Surveys also showed that the land occupied by reeds, high grasses, and aquaculture ponds are favorable sites. The extensive reed beds of Phragmites australis predominate in many areas, and there are also extensive grasses and sedge marshes such as Scirpus planiculmis, S. triqueter, Carex scabrifolia, Cortaderia celloana, Panicum psilopodium, and saline marshes such as goosefoot Suaeda salsa. Besides this vegetation, the area also includes salt pans, farm land, aquaculture ponds, and land for cultivating economic plants such as reed and Spartina anglica. Abundant food is also one of the factors attracting cranes. The examination of cranes' stomach contents has shown that they feed on small fish and crabs, grass seeds, and grass roots. (Management Office of YBR, 1995). Cranes usually remain far from roads to avoid interference from human beings.

Four principal environmental variables were determined, based on the above description and thought to be potentially relevant to the habitat of cranes. They are land cover type, productivity of food, salinity, and extent of the road network. These variables were transformed into category or ordinary variables and recorded as dummy values prior to being included in the regression model (Pereira, 1991), as shown in Table 1. 
Table 1

Independent variables and their definitions ${ }^{\mathrm{a}}$

\begin{tabular}{|c|c|}
\hline Variable name & Definition \\
\hline FOOD & $\begin{array}{l}\text { Three categories: } 0-200 \mathrm{~g} / \mathrm{m}^{2}, 200-400 \mathrm{~g} / \mathrm{m}^{2} \text {, } \\
>400 \mathrm{~g} / \mathrm{m}^{2}\end{array}$ \\
\hline ROAD & Distance to road: $0-600 \mathrm{~m}, 600-1200 \mathrm{~m},>1200 \mathrm{~m}$ \\
\hline LANDCVR & $\begin{array}{l}\text { Nine categories: seawater, mudflat, Spartina anglica, } \\
\text { Suaeda salsa, aquaculture land, salt pan, grass land, } \\
\text { reed, farm land }\end{array}$ \\
\hline SALINITY & Three categories: $0-15 \mathrm{mg} / 1,15-30 \mathrm{mg} / 1,>30 \mathrm{mg} / 1$ \\
\hline
\end{tabular}

a Each category of each variable is recorded as 1, 2, 3, etc., from left to right.

The scale of the variables, survey time, and processing methods in GIS are described as follows:

1. The variable land cover is generated by using supervised classification of the remote sensing data from Landsat TM, 1988. Compared with current field survey, there were no significant changes for land cover type in YBR during the past decade. Therefore the passage of time would not affect the research results. As shown in Table 1, there are nine categories for land cover.

2. Food productivity was obtained from a field work in November 1995 (Ma et al., 1998). The sample sites were digitized from 1:70,000 map, and the point coverage was formed and converted into grid format. The food productivity map was created by interpolating the field data and then converted into an ordinary variable (Table 1 ).

3. Variable salinity was obtained in the same way as that for food productivity.

4. The road network was digitized from the map at a scale of 1:70,000, and then converted into grid format. The range of distance to road is classified into three categories according to field knowledge that humans have a great influence on cranes within $600 \mathrm{~m}$, moderate influence from 600 to $1200 \mathrm{~m}$, and less influence further than $1200 \mathrm{~m}$ (Zhou and Su, 1990).

5. The dependent variable distribution of cranes was obtained from the results of presence/absence surveys carried out in 1991-1994 (Management Office of YBR, 1995), as shown in Fig. 1. Value 1 is assigned to the cells where cranes were present (active sites in Fig. 1), and value 0 is assigned to the cells where cranes were absent.

\subsection{Model design}

Since the binary nature of crane activity, and one of the independent variables (i.e. land cover) is qualitative, logistic regression is an appropriate method to model the habitats (Press and Wilson, 1978).
The role of each independent variable was tested statistically in order to find out whether cranes actually discriminate among sites based on the above environmental variables. If they do, the comprehensive characteristics of a variable at locations that cranes have selected as favorable habitat (active sites) should differ from the characteristics at locations (inactive sites) they avoided (Kvamme, 1985). For ordinary variables (food productivity, salinity, road network), the Kolmogorov test was used to identify significant differences of variable characteristics between active and inactive sites; and chisquare test for category variable (Upton and Fingleton, 1985; Tao, 1994).

Identification of suitable habitats based on environmental variables requires the establishment of a control group of samples, randomly selected from the population of all inactive sites, against which the data for all active sites can be compared. The results obtained from the statistical model are useful only when the sample obtained is representative for the population. Therefore the sampling scheme is the basis for generating habitat model successfully. It is affected by the following two factors. First, because inactive sites correspond to the vast majority of the study area [Fig. 1], larger variation is expected in environmental attributes for this group. A ratio of inactive to active sites larger than one is thus desirable (Kvamme, 1985). There are 37,529 active cells in the database and the sample should therefore include a value larger than that for inactive cells. Second, the spatial autocorrelation structure in the environmental variables has to be considered in order to assess how to minimize it through systematic sampling (Haining, 1980). The spatial autocorrelation analysis was used to identify whether the variable value of a given site is correlated with the value of its neighboring sites. One method of reducing the spatial autocorrelation is to group small areas together into larger units that will be more nearly independent of each other (Hall 1988). Moran's I coefficient (Cliff and Ord, 1981; Upton and Fingleton, 1985; Turner et al., 1990) was applied to assess the spatial autocorrelation.

Since the shape of the reserve is linear, different sampling lags were used in row and column directions, respectively, to keep the contained cells as typical as possible while ensuring the sampled data had no spatial autocorrelation. The final sampling schedule is that each 2nd cell in the database is selected in row direction and each 8 th cell in column direction. This yields a sample of 45,909 inactive sites, and Moran's I coefficients drop to values from 0.47 for food productivity, down to 0.17 for land cover. After sampling, the environmental data are named as FOODSMP, ROADSMP, LANDCVRSMP, and SALINITYSMP corresponding to the four independent variables FOOD, ROAD, LANDCVR, AND SALINITY respectively (Table 1), which will be used to calculate the regression coefficients of the habitat model. 
The model is tested through calculating matching coefficient of the observed and predicted presence/ absence data (Pereira, 1991; Buckland and Elston, 1993; Augustin et al., 1996). In order to do this, the outputs of the logistic regression model measuring the probability of a cell being suitable habitat are converted to dichotomous $1 / 0$ data through specification of a cutoff point. Any cells with values below a given cutoff point are considered as unsuitable and assigned value 0 . This test measures what percentage of cells predicted to be suitable actually contain cranes and, conversely, the percentage of cells predicted to be unsuitable where cranes are indeed absent. As shown in Table 2, $m_{1}$ and $m_{2}$ represent the numbers of correctly classified cells, while $n_{1}$ and $n_{2}$ represent the numbers of misclassified cells. The matching coefficient $\left(m_{1}+m_{2}\right) / n$ is used to assess the proportion of correctly classified cells, which is considered as total Correctly Classified Rate (CCR) for both active and inactive cells. Thus the total CCR represent the accuracy of the model. In addition, the CCR for active cells $m_{1} / m n_{1}$ is used to assess the proportion of correctly classified active cells, and the CCR for inactive cells $m_{2} / m n_{2}$ to assess the proportion of correctly classified inactive cells.

\subsection{Core zone design}

Designing the core is based on the suitable habitats predicted by the regression model. Since the habitats are usually discontinuous patches, the following criterion is considered in design to make the core more scientific. If a suitable patch is less than $3.5 \mathrm{~km}^{2}$, which is the minimum habitat requirement for a breeding pair (Zhou and $\mathrm{Su}, 1990)$, it will be neglected in the design of the core area since the patch is too small to supply enough space and food for the cranes. Conversely, if a suitable patch is larger than $3.5 \mathrm{~km}^{2}$, it will be designated as core area, and furthermore the small unsuitable clusters within this patch (if clusters exist) should be incorporated in the surrounding area for the purpose of habitat restoration.

\section{Results}

\subsection{Habitat model}

The test values and the critical values used for statistical tests with significant level of 0.05 for the independent variables are listed in Table 3. All the test values are larger than their critical values, so that all four environmental variables significantly affect the distribution of cranes. Therefore they are selected to generate the habitat model.

Four coefficients $0.256,0.556,0.392$ and -0.782 corresponding to the sampled data FOODSMP, ROADSMP, LANDCVRSMP, and SALINITYSMP and a constant -3.552 are yielded through logistic regression. Based on these coefficients, the probability of the presence of cranes at any given cell is calculated by the logistic model as follows:

$$
\begin{aligned}
\log \left(\frac{p}{1-p}\right)= & -3.552+0.256 \times \text { FOOD }-0.782 \\
& \times \text { SALINITY }+0.392 \\
& \times \text { LANDCVR }+0.556 \times \text { ROAD }
\end{aligned}
$$

Where $p$ represents the estimated probability of presence of cranes at a given cell, and FOOD, SALINITY, LANDCVR, and ROAD (Table 1) are unsampled environmental variables. The probability $p$ is represented as a map of continuous probability values, and then transformed into two categories, i.e. presence/ absence data, by applying a probability level of 0.5 as

Table 2

Matching counts: a method to assess the matching of predicted cells and observed cells

\begin{tabular}{llll}
\hline Observed distribution & \multicolumn{3}{l}{ Predicted distribution } \\
\cline { 2 - 4 } & Present & Absent & Total \\
\hline Present & $m_{1}$ & $n_{1}$ & $m n_{1}$ \\
Absent & $n_{2}$ & $m_{2}$ & $m n_{2}$ \\
Total & & & $n$ \\
\hline
\end{tabular}

Table 3

\begin{tabular}{|c|c|c|c|c|c|}
\hline Sampled variables & $\begin{array}{l}\text { Classes of } \\
\text { variables }\end{array}$ & $\begin{array}{l}\text { Active } \\
\text { cells }\end{array}$ & $\begin{array}{l}\text { Inactive } \\
\text { cells }\end{array}$ & $\begin{array}{l}\text { Test } \\
\text { values }\end{array}$ & $\begin{array}{l}\text { Critical } \\
\text { values }\end{array}$ \\
\hline \multirow[t]{4}{*}{ FOODSMP } & & & & $2.26 \times 10^{8}$ & $1.63 \times 10^{7}$ \\
\hline & 1 & 4283 & 6802 & & \\
\hline & 2 & 19,902 & 28,787 & & \\
\hline & 3 & 13,344 & 10,320 & & \\
\hline \multirow[t]{4}{*}{ ROADSMP } & & & & $1.67 \times 10^{8}$ & $1.63 \times 10^{7}$ \\
\hline & 1 & 3692 & 8607 & & \\
\hline & 2 & 5303 & 6793 & & \\
\hline & 3 & 28,534 & 30,509 & & \\
\hline \multirow[t]{10}{*}{ LANDCVRSMP } & & & & $2.12 \times 10^{4}$ & 15.51 \\
\hline & 1 & 112 & 6328 & & \\
\hline & 2 & 0 & 1124 & & \\
\hline & 3 & 44 & 3588 & & \\
\hline & 4 & 2368 & 7257 & & \\
\hline & 5 & 6208 & 7403 & & \\
\hline & 6 & 4142 & 5141 & & \\
\hline & 7 & 12,361 & 6296 & & \\
\hline & 8 & 11,444 & 3841 & & \\
\hline & 9 & 850 & 4931 & & \\
\hline \multirow[t]{4}{*}{ SALINITYSMP } & & & & $3.91 \times 10^{8}$ & $1.63 \times 10^{7}$ \\
\hline & 1 & 32,603 & 29,514 & & \\
\hline & 2 & 4634 & 14,750 & & \\
\hline & 3 & 292 & 1645 & & \\
\hline
\end{tabular}

Statistic tests for the environmental variables' significant difference affecting the distribution of cranes 
the optimal cutoff point [Fig. 2(a)]. Those cells where the probability is $0.5 \sim 1.0$ were considered as suitable habitats in Fig. 2(a).

After Fig. 2(a) is generated, the corresponding counts $m_{1}, n_{1}, m_{2}$, and $n_{2}$ defined in Table 2 are obtained. The total CCR is $71.2 \%$ [Fig. 3(b)], which is considered as the accuracy of the model. At the same cutoff point, the CCR for active cells counts $69.8 \%$ of cells observed to be active [curve 1 in Fig. 3(a)], and the CCR for inactive cells counts $71.3 \%$ of cells observed to be inactive [curve 2 in Fig. 3(a)]. The results of total CCR, CCR for active cells, and CCR for inactive cells show that the model has a generally satisfactory accuracy.

\subsection{Designed core zone}

The designed core is shown schematically in Fig. 2(b), covering $944.8 \mathrm{~km}^{2}$, and obviously larger than the original $375.5 \mathrm{~km}^{2}$ [Fig. 1(b)]. Comparing Figs. 1 and 2(b), it can be seen that the new core contains more suitable habitats than the original one.

\section{Discussion}

\subsection{Habitat model}

The agreement between the predicted and observed habitats is affected by the selection of the cutoff point.
The CCR changes with the cutoff point for probability of activity (Fig. 3). As shown in Fig. 3(b), the total CCR for both active and inactive cells increases from $14.9 \%$ for a cutoff point of 0.1 to $94.9 \%$ for a cutoff point of 0.9. Its changes with the cutoff point are consistent with the CCR for inactive cells, which also increases with the value of the cutoff point, as indicated by the curve 2 in Fig. 3(a). This can be explained in that the inactive cells are predominant in the study area, so that CCR for inactive cells is the key contributor to total CCR. Nevertheless, CCR for active cells decreases from $99.8 \%$ for a cutoff point of 0.1 to $0.1 \%$ for a cutoff point of 0.9 , as indicated by the curve 1 in Fig. 3(a). It is a descending curve with the value of the cutoff point and is trailed with contrary to the curve of total CCR, which is a ascending curve as shown in Figure $3 b$. Therefore although the total CCR can represent the accuracy of the model, it can not represent the accuracy of modeling and predicting the active cells.

However the purpose of the core design is to conserve the active sites. Thus, it is necessary to get a higher CCR for active cells, and at the same cutoff point a generally satisfactory total CCR should be ensured. To obtain the optimal cutoff point, the sum (curve 3 ) of curves 1 and 2 is plotted in the Fig. 3(a), and the cutoff point corresponding to the peak of curve 3 is considered as optimal (Pereira, 1991). The peak of curve 3 corresponds to a probability point of 0.5 . A probability level of 0.5 is thus accepted as the optimal cutoff point. In addition, it (a)

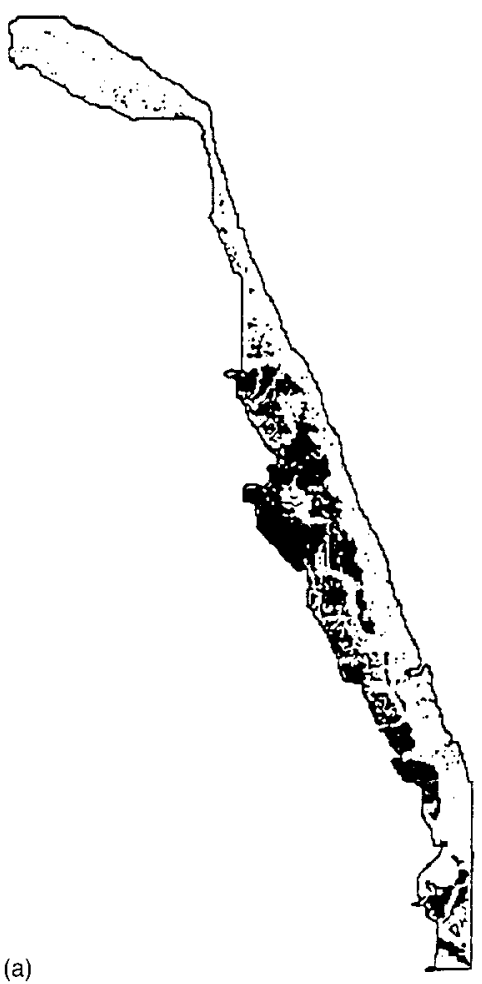

suitable habitats

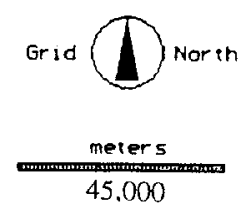

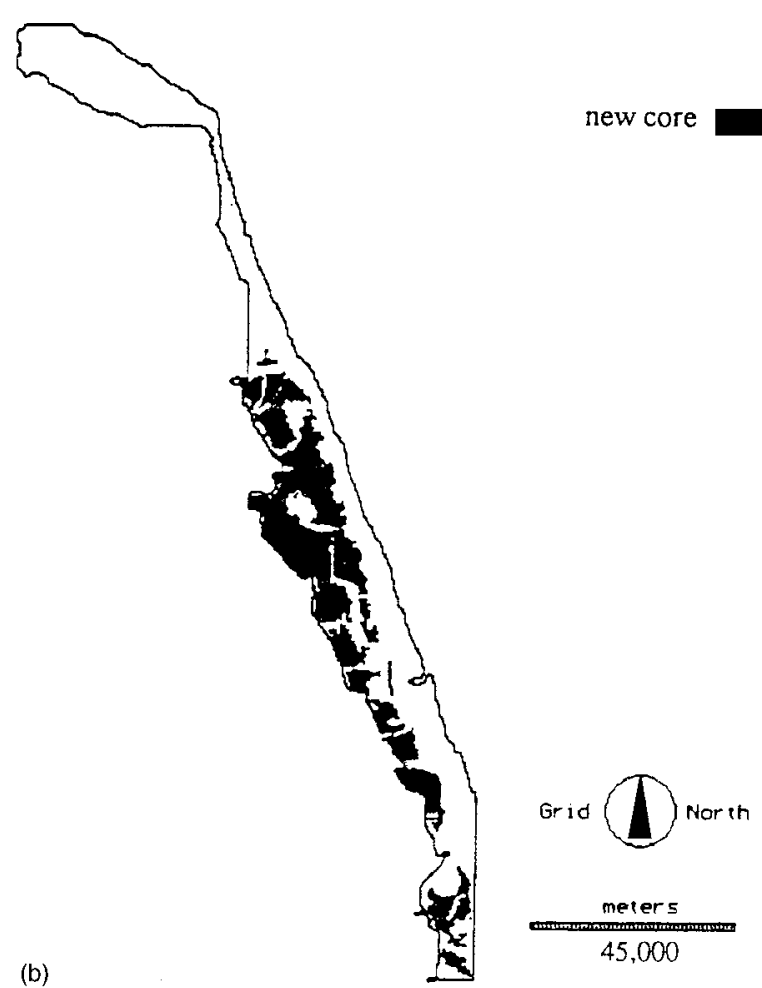

(b)

Fig. 2. (a) Predicted suitable habitats in YBR; (b) new designed core allocation in YBR. 


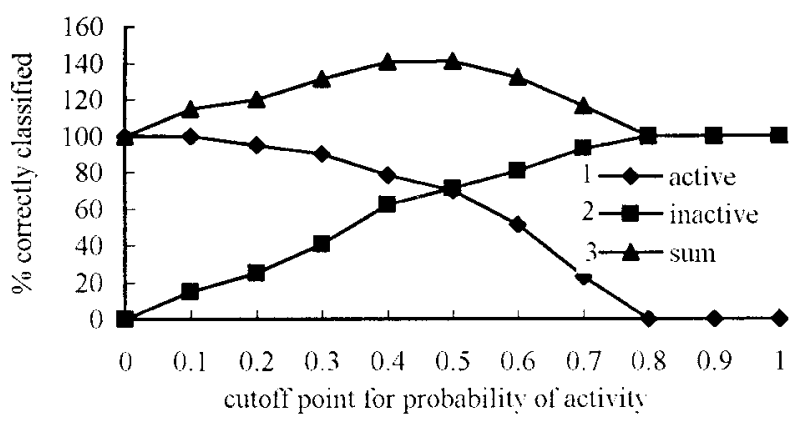

(a)

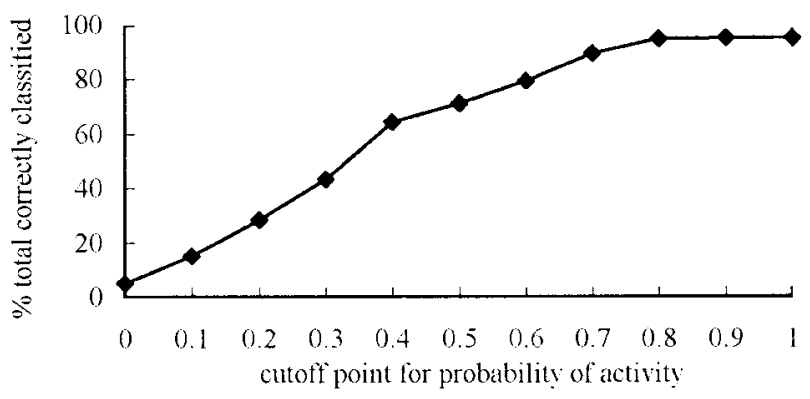

(b)

Fig. 3. Correctly classified rates (CCR) of predicted data: (a) curve 1, CCR for active cells, calculated by $m_{1} / m n_{1}$; curve 2 , CCR for inactive cells, calculated by $m_{2} / m n_{2}$; curve 3 is used to identify the optimal cutoff point, which is obtained from the sum of curve 1 and curve 2, $\left(m_{1} / m n_{1}\right)+\left(m_{2} / m n_{2}\right)$; (b) CCR for both active and inactive cells, calculated by $\left(m_{1}+m_{2}\right) / n$.

is thought reasonable in the statistics that the areas where cranes are present with more than $50 \%$ probability are considered as suitable habitats.

\subsection{Habitat and core zone}

The core zone has the function of habitat conservation and restoration. If the suitable habitats were not protected as core, they might be gradually fragmented, and then irreversibly lost. Nevertheless, if fragmentation was not so serious, and was preserved in the core without delay, they might recover after a period of time.

The suitable habitats are discontinuous fragments in the middle and south of YBR [Fig. 2(a)] and even some small clusters distributed to the north of YBR. The fragmentation is considered to result from human interference because most fragments, such as those in the north, are located outside the original core and thus are not effectively conserved. The fragmentation is so serious that these habitats will disappear forever.

In considering the minimum habitat requirement of cranes, small fragments such as those in the north of YBR will not be designated as core area even though they are suitable habitats [Fig. 2(a)]. In addition, habitat restoration should be considered in the core design.

\subsection{Problems in core design}

For the designated core zone [Fig. 2(b)], there are still some unresolved problems, for example, these core areas are not contiguous. According to the core definition by UNESCO (1987), a reserve might contain several core areas, so that if the distance between two areas was too far, they could be designed as two discontinuous cores; otherwise they should be combined into one core. However, how to determine the acceptable minimum distance between two areas, remains a problem in practical operation.

The second dilemma is whether it is necessary to create corridors, as used for connecting isolated reserves in reserve design (Hubbell and Foster, 1986; Simberloff and Cox, 1987), to connect the discontinuous core areas. Also, whether the method of creating corridors suitable for reserve design could be used for core design, especially for the core preserving the birds' habitat.

The third problem is that the designated core areas are along the left boundary of reserve [Fig. 2(b)], which will cause the buffer zone and the transition zone to extend outside the existing reserve boundary and would occupy more cultivated land. To programme the core zone according to this design, collaboration of local government is necessary.

\section{Conclusions}

A logistic regression model is developed to predict suitable habitats for the red crowned crane. The correctly classified rate of the model is $71.2 \%$ at the optimal cutoff point of 0.5 . Based on these habitats, a new core zone is designated from consideration of the minimum habitat requirement and possibility of restoration. The new core area is $944.8 \mathrm{~km}^{2}$, and much larger than the original $375.5 \mathrm{~km}^{2}$. The designated core can conserve and restore more suitable habitats than the original one. To ensure that the core is more practical, research on core design should be continued as part of general study of the whole interior structure of reserve.

\section{Acknowledgements}

We would like to thank Mr. Wang Hui, the staff working in the Yancheng Biosphere Reserve, Mr. Liu Xiping, the director of the reserve, for their help in supplying data and information about the reserve. We also would like to thank Ms. Zhao Xianying, the general secretary of Chinese National Committee for MAB Program, and Mr. Han Nianyong, the director of the Committee, for their help during the research. Especially, we thank Dr. T.R. New, the Australasian Editor of Biological Conservation, for comments on earlier drafts of manuscript. 


\section{References}

Augustin, N.H., Mugglestone, M.A., Buckland, S.T., 1996. An autologistic model for the spatial distribution of wildlife. Journal of Applied Ecology 33, 339-347.

Blouin, M.S., Connor, E.F., 1985. Is there a best shape for nature reserves? Biological Conservation 32, 277-288.

Buckland, S.T., Elston, D.A., 1993. Empirical models for the spatial distribution of wildlife. Journal of Applied Ecology 30, 478-495.

Buckley, R., 1982. The habitat-unit model of island biogeography. Journal of Biogeography 9, 334-344.

Cliff, A.D., Ord, J.K., 1981. Spatial Processes: Models and Applications. Pion Limited, London.

Diamond, J.M., 1967. Island biogeography and design of natural reserves. In: May, R.M. (Ed.), Theoretical Ecology: Principles and Applications. Blackwell, Oxford, pp. 163-186.

Haining, R. (1980). Spatial autocorrelation problem. In: Herbert, D.T., Johnston, R.J. (Eds.), Geography and the Urban Environment, Cambridge University Press, England (Cambridge) vol. 3. pp. 43.

Hall, P., 1988. On confidence intervals for spatial parameters estimated from nonreplicated data. Biometrics 44, 271-277.

Higgs, A.J., 1981. Island biogeography theory and nature reserve design. Journal of Biogeography 8, 117-124.

Higgs, A.J., Usher, M.B., 1980. Should nature reserves be large or small? Nature 285, 568-569.

Hubbell, S.P., Foster, R.B., 1986. Commonness and rarity in a neotropical forest: implication for tropical tree conservation. In: Soule, M.E. (Ed.), Conservation Biology: The Science of Scarcity and Diversity. Sinauer, Sunderland, pp. 205-231.

IUCN, 1987. Buffer zones: development that protects parks. IUCN Bulletin 18, 10-11.

Kvamme, K.L., 1985. Determine empirical relationships between the natural environment and pre-historic site locations: a hunter-gatherer example. In: Carr, C. (Ed.), For Concordance in Archeological Analysis. Wesport, Kansas City, KS, pp. 208-238.

Liu, B., 1990. Winter numbers distribution of red crown crane on seaboard of Yancheng of Jiangsu Province. ACTA Ecologica SINICA 10, 234-235 (in Chinese).

Ma, Z.J., Li, W.J., Wang, Z.J., Tang, H.X., 1998. The winter habitat selection of red-crown crane in Yancheng biosphere reserve. AMBIO 27, 461-464.

MacArthur, R.H., Wilson, E.O., 1967. The Theory of Island Biogeography. Princeton University Press, Princeton, NJ.

Management Office of YBR, 1995. The Comprehensive Survey Report on Yancheng Biosphere Reserve. Local Government of Jiangsu Province, Jiangsu, China (in Chinese).

Margules, C., Higgs, A.J., Rafe, R.W., 1982. Modern biogeographic theory: are there any lessons for nature reserve design? Biological Conservation 24, 115-128.

Pereira, J.M., 1991. GIS-based habitat modeling using logistic multiple regression: a study of the Mt. Graham red squirrel. Photogrammetric Engineering and Remote Sensing 57, 1475-1486.

Press, S.J., Wilson, S., 1978. Choosing between logistic regression and discriminate analysis. Journal of American Statistic Association 73, 699-705.

Simberloff, D., Cox, J., 1987. Consequences and costs of conservation corridors. Conservation Biology 1, 63-71.

Tao, S., 1994. Applied Statistics Method. Chinese Environmental Sciences Press, Beijing (in Chinese).

Toxopeus, A.G., Wijingaarden, W.V., 1994. An interactive spatial modeling (ISM) system for the management of the Cibodas Biosphere Reserve (west Java, Indonesia). ITC Journal, 4, 385-391.

Turner, S.J., O’Neill, R.V., Conley, W., 1990. Parttern and scale: statistic for landscape ecology. In: Turner, M.G., Gardner, R.H. (Eds.), Quantitative Methods in Landscape Ecology. Springer Verlag, NY. pp. 17-51.

UNESCO, 1987. Practical Guide to the Man and Biosphere Programme (MAB). Unesco, Paris.

Upton, G.J.G., Fingleton, B., 1985. Spatial Analysis by Example, vol. 1: Point Pattern and Quantitative Data. Wiley, New York.

Usher, M.B., 1986. Species conservation evaluation attributes, criteria and values. In: Usher, M.B. (Ed.), Biological Conservation and Evaluation. Chapman and Hall, London, pp. 3-44.

Yan, F.T., 1991. Wintering distribution and biological study of red crown cranes in Yancheng beach. Chinese Journal of Zoology 26, 34-36 (in Chinese).

Zhou, D.S., Su, L.Y., 1990. Primary study for red crown cranes in their habitats. In: Forestry Bureau of Heilongiiang Province, International Conservation and Research for Crane. Chinese Forestry Press, Beijing, pp. 54-58 (in Chinese). 